nature of the substitute used for repair. These results should be confirmed in a larger population with a longer follow-up.

\section{References}

1. Haydock D, Barratt-Boyes B, Macedo T, Kirklin JW, Blackstone E. Aortic valve replacement for active infectious endocarditis in 108 patients. A comparison of freehand allograft valves with mechanical prostheses and bioprostheses. J Thorac Cardiovasc Surg. 1992;103: $130-9$.
2. Pulpon LA, Crespo MG, Sobrino M, et al. Recalcitrant endocarditis successfully treated by heart transplantation. Am Heart J. 1994; 127(4 Pt 1):958-60.

3. David TE. The surgical treatment of patients with prosthetic valve endocarditis. Semin Thorac Cardiovasc Surg. 1995;7:47-53.

4. Obadia JF, Raisky O, Sebbag L, Chocron S, Saroul C, Chassignolle JF. Monobloc aorto-mitral homograft as a treatment of complex cases of endocarditis. J Thorac Cardiovasc Surg. 2001;121:584-6.

5. David TE, Feindel CM, Armstrong S, Sun Z. Reconstruction of the mitral anulus. J Thorac Cardiovasc Surg. 1995;110:1323-32.

\title{
Origin of left subclavian artery from ascending aorta: A variant of double aortic arch
}

K. Mahadevan Krishnamoorthy, DM, DNB, Hemant Madan, MD, and Jaganmohan A. Tharakan, DM, Trivandrum, India
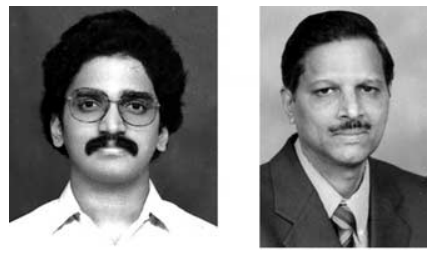

Krishnamoorthy (left) and Tharakan

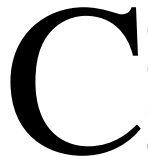

ongenital anomalies of aortic arch include abnormalities of branching or position and supernumerary or interrupted arch. An embryologic explanation is provided for a hith-

erto unreported association of the origin of left subclavian artery (LSCA) from the ascending aorta (AA) in a patient with tetralogy of Fallot (TOF) and right aortic arch.

\section{Clinical Summary}

A 1-year-old girl with TOF had normal peripheral pulses. Chest radiography showed a right aortic arch. She was catheterized to delineate coronary anatomy, which proved to be normal. In addition, a vessel was seen arising from the AA. Thus, an aortic root angiogram in frontal and lateral views was performed. A right aortic arch was seen. The LSCA was the first branch of the AA. Figure 1 shows the frontal view, and Figure 2 shows the lateral view. Subsequent branches of the aortic arch were the left common carotid, right common carotid, and right subclavian artery (RSCA), in that order.

\section{Discussion}

Right Arch With Anomalous Left Subclavian Artery. Mirror image branching is the most frequent form of arrangement of the arch vessels in right aortic arch; $98 \%$ have congenital heart disease. TOF is present in $48 \%$ of patients. Right aortic arch with anomalous LSCA

\footnotetext{
From the Sree Chitra Tirunal Institute for Medical Science and Technology, Trivandrum, India.

Received for publication August 22, 2003; revisions received February 23, 2004; accepted for publication March 2, 2004.

Address for reprints: K. M. Krishnamoorthy, DM, DNB, Sree Chitra Tirunal Institute for Medical Sciences and Technology, Trivandrum, India (E-mail: saikm@sctimst.ker.nic.in).

J Thorac Cardiovasc Surg 2006;131:245-7

$0022-5223 / \$ 32.00$

Copyright (C) 2006 by The American Association for Thoracic Surgery doi:10.1016/j.jtcvs.2004.03.059
}

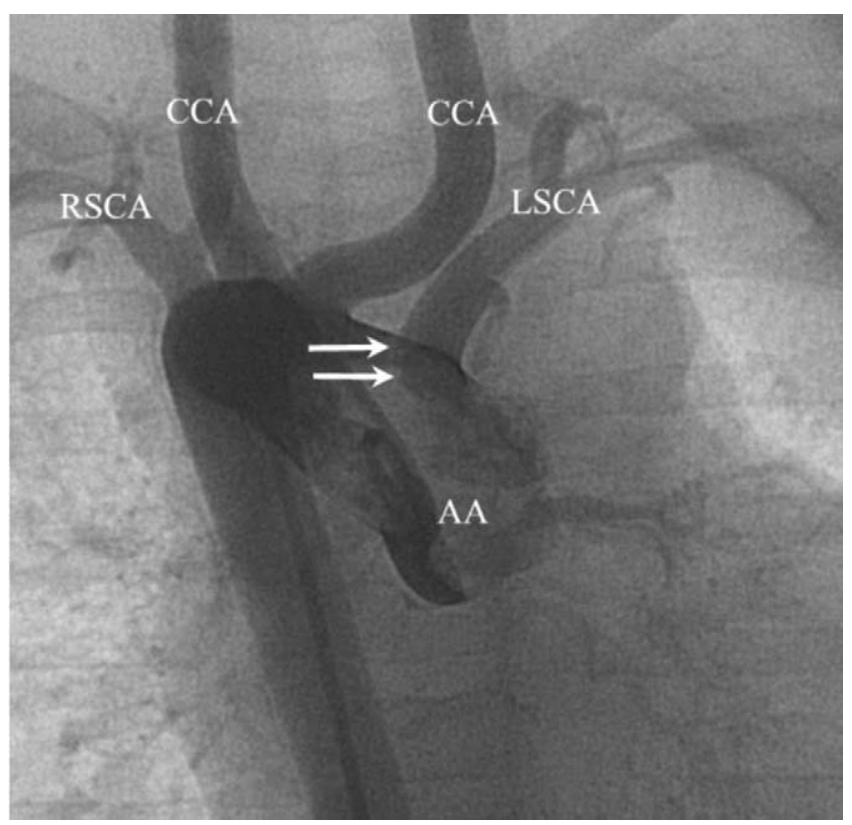

Figure 1. Aortic root angiogram; frontal view. $A A$, Ascending aorta; $L S C A$, left subclavian artery; $R S C A$, right subclavian artery; $C C A$, common carotid artery. Outline of the origin of LSCA (white arrows).

is described with the following sequence of branches: left common carotid, right common carotid, and LSCA. LSCA is the fourth branch and arises from the upper descending aorta. This has a lower incidence than a right arch with mirror image branching. ${ }^{1}$ In a study of anomalous SCA in TOF with a right arch, all of the 16 patients had anomalous LSCA arising from the distal portion of the right arch without the formation of a diverticulum. ${ }^{2}$ Origin from the AA has not been described. 


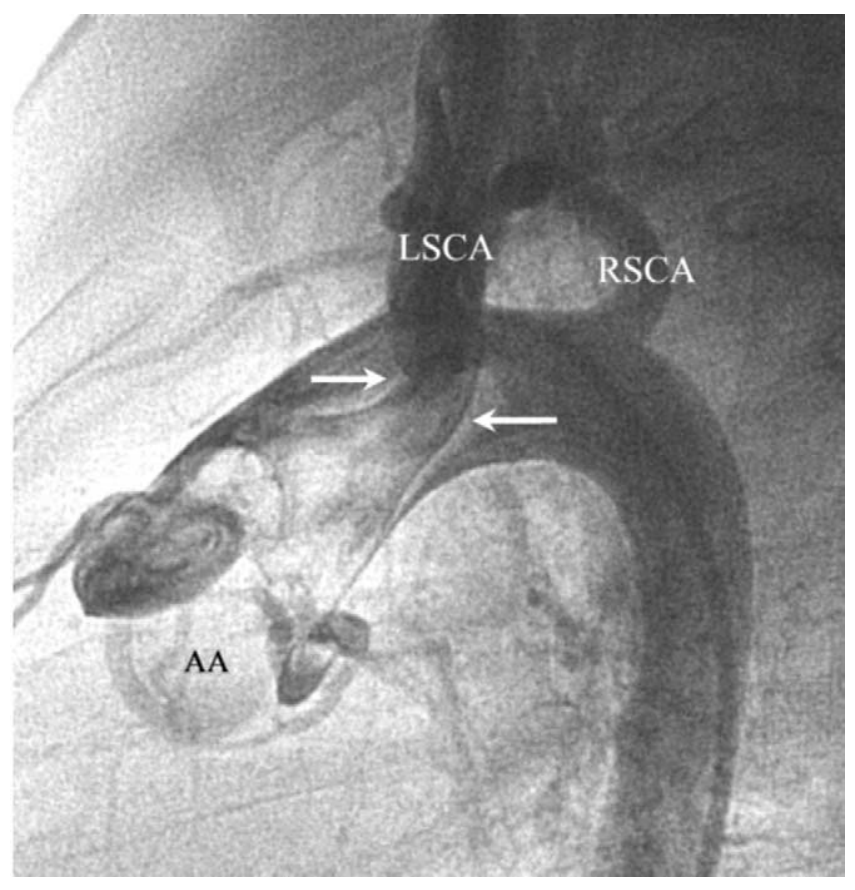

Figure 2. Aortic root angiogram; lateral view. $A A$, Ascending aorta; $L S C A$, left subclavian artery; $R S C A$, right subclavian artery; CCA, common carotid artery. Outline of the origin of LSCA (white arrows).

Development of Left Arch. The cranial parts of the dorsal aortae along with the first 8 segments form the dorsal aortic roots. The 2 dorsal aortic roots develop further according to lateralization. The root of the AA is formed by the posterior part of truncus arteriosus. The distal AA, right brachiocephalic artery, and arch up to the origin of the left common carotid artery develops from the left dorsal aortic root. The right dorsal aortic root disappears. The fourth left primitive arch artery gives rise to the aortic arch from the point of origin of the left common carotid artery up to the LSCA. The right fourth aortic arch forms the proximal RSCA, and the right seventh intersegmental artery (ISA) forms the distal RSCA. The LSCA is formed entirely by the left seventh ISA without contribution from the primitive arch complex. The eighth left ISA connects the left arch with the descending aorta. The LSCA originates from the arch between the seventh and eighth left ISAs. The right dorsal aorta from the point of origin of the seventh right ISA to the former's junction with the left dorsal aorta disappears entirely.

Development of Right Arch. The relative contribution of the primitive arch complexes is reversed in a mirror image right aortic arch. The terminal part of the AA, the left brachiocephalic artery, and the arch up to the origin of the right common carotid artery develop from the right dorsal aortic root. The left dorsal aortic root disappears. The fourth right arch artery forms the aortic arch from the origin of the right common carotid artery to the RSCA. RSCA is formed by the right seventh ISA. The left fourth aortic arch forms the proximal LSCA, and the left seventh ISA forms the distal LSCA. The left dorsal aorta from the point of origin of the seventh left ISA to the former's junction with the right dorsal aorta disappears.

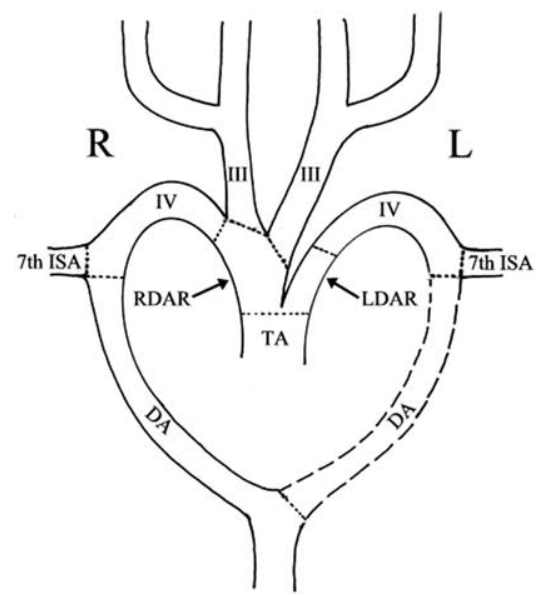

Figure 3. Embryology of the anomaly. $R$, Right side; $L$, left side; III, third arch; IV, fourth arch; ISA, intersegmental artery; RDAR, right dorsal aortic root; $L D A R$, left dorsal aortic root; $T A$, truncus arteriosus; $D A$, descending aorta. Portion that disappears (dashed lines); boundary between various segments (dotted lines). Only the third and fourth arches are shown. Other abbreviations as in Figure 1. Only the fourth arch (and not the seventh ISA) can connect to the dorsal aortic root.

Embryologic Explanation. Anomalies of the aortic arch can be explained by the double aortic arch system of Edwards. ${ }^{3}$ We propose that the anomaly in this patient, origin of LSCA from the AA with a right aortic arch, represents a form of double aortic arch. On the basis of this discussion, one crucial point may be noted. The seventh ISA (developing into SCA) cannot arise directly from the dorsal aortic root (which eventually forms the distal AA). Only the fourth aortic arch can connect to the dorsal aortic root.

In this patient, a regular right arch developed, as described previously. In addition, the left dorsal aortic root (which forms the left aortic arch) has undergone only partial (not full, as is normal) involution. It is present up to the origin of the seventh left ISA. The distal aspect of truncus arteriosus has connected to the remnant of the left dorsal aortic root. The proximal LSCA represents the persistent left fourth aortic arch, and the seventh left ISA forms the distal LSCA. Thus, this anomaly will represent a type of double aortic arch. Figure 3 is a schematic representation of our postulation. Anatomic variations of the double aortic arch are attributable to the relative size of the 2 arches, the partial atresia of 1 arch, and the side of the ductus and descending aorta. Partial obliteration of 1 arch usually involves the anterior (left) arch. ${ }^{4}$ This was so in our patient.

Further Evidence for Double Arch. In a double aortic arch, there is persistence of both the right and left fourth aortic arches. Parts of the arch on either side may undergo atresia. The right arch tends to be higher in location compared with the left arch, as was seen in our patient. In a double aortic arch, each arch will cross over the ipsilateral bronchus. The proximal portion of the LSCA crossed the left bronchus in our patient (Figure 1), confirming that the proximal LSCA is a remnant of the left arch. Although usually an isolated abnormality, double aortic arch can occur with congenital heart disease. TOF, as in our case, is the most common congenital heart disease associated with double aortic arch. ${ }^{5}$ 


\section{Conclusion}

Origin of LSCA from the AA can be explained by Edwards' double arch hypothesis. ${ }^{3}$ The right arch has fully developed. In addition, there is persistence of a part of the left fourth aortic arch and seventh left ISA in tandem forming the LSCA.

\section{References}

1. Hastreiter AR, D'Cruz IA, Cantez T, Namin EP, Licata R. Right-sided aorta. I. Occurrence of right aortic arch in various types of congenital heart disease. II. Right aortic arch, right descending aorta, and associated anomalies. Br Heart J. 1966;28:722-39.

2. Velasquez G, Nath PH, Castaneda-Zuniga WR, Amplatz K, Formanek A. Aberrant left subclavian artery in tetralogy of Fallot. Am J Cardiol. 1980;45:811-8.

3. Edwards JE. Anomalies of the aortic arch system. Birth Defects. 1977; 13:47-63.

4. Gross R, Ware P. The surgical significance of aortic arch anomalies. Surg Gynecol Obstet. 1946;83:435-48.

5. Higashimo SM, Ruttenberg HD. Double aortic arch associated with complete transposition of great vessels. Br Heart J. 1968;30: $579-81$.

\title{
Intermediate outcomes of fenestrated Fontan procedures
}

\author{
S. Garekar, MD, ${ }^{a}$ H. L. Walters, III, MD, ${ }^{b}$ R. E. Delius, MD, ${ }^{b}$ R. L. Thomas, PhD, ${ }^{c}$ and R. D. Ross, MD, ${ }^{a}$ Detroit, Mich
}

$\mathrm{T}$ he fenestrated Fontan $(\mathrm{FF})$ procedure is associated with better hemodynamics postoperatively than the modified Fontan procedure without a fenestration. ${ }^{1,2}$ Although a fenestration improves cardiac output, there is a cost of right-to-left shunting, cyanosis, and the subsequent risk of thromboembolism.

Our goal was to evaluate our experience with FF procedures. Specifically, we sought (1) to assess the outcomes of closed fenestrations, (2) to determine the rate of spontaneously closed fenestrations, and (3), among patients with patent fenestrations, to determine whether a clinical or laboratory variable could be used to predict their outcomes.

After institutional review board approval, $23 \mathrm{FF}$ procedures with no other source of significant right-to-left shunt were identified. The cardiac lesion in the majority of patients (16/23 [70\%]) was hypoplastic left heart syndrome.

\section{Pre-Fontan Catheterization Hemodynamics}

The average mean pulmonary artery pressure was $11 \pm 2.8 \mathrm{~mm}$ $\mathrm{Hg}$. The mean pulmonary vascular resistance (PVR) was $2.3 \pm 1.5$ indexed Wood units. The mean systemic ventricular end-diastolic pressure was $7.8 \pm 2.6 \mathrm{~mm} \mathrm{Hg}$.

\footnotetext{
From the Division of Cardiology, Department of Pediatrics, ${ }^{a}$ the Division of Pediatric Cardiovascular Surgery, ${ }^{\mathrm{b}}$ and the Department of Pediatrics, ${ }^{\mathrm{c}}$ Children's Hospital of Michigan, Detroit, Mich.

Received for publication Aug 1, 2005; revisions accepted Sept 2, 2005; accepted for publication Sept 8, 2005.

Address for reprints: Swati Garekar, MD, Pediatric Cardiology, Children's Hospital of Michigan, 3901 Beaubien Blvd, Detroit, MI 48201 (E-mail: swatigar@gmail.com).

J Thorac Cardiovasc Surg 2006;131:247-9

$0022-5223 / \$ 32.00$

Copyright $\odot 2006$ by The American Association for Thoracic Surgery

doi:10.1016/j.jtcvs.2005.09.004
}

\section{Surgical Results}

The mean age at the time of the operation was $24.7 \pm 9$ months. Twenty-two of the 23 patients received the lateral tunnel Fontan procedure, and the remaining patient received an extracardiac conduit. The fenestration was a single $4-\mathrm{mm}$ punch in 14 patients. Additional procedures performed along with the Fontan procedure were pulmonary artery patch angioplasty $(n=4)$ and atrioventricular (AV) valvuloplasty $(\mathrm{n}=3)$. The mean hospital stay after surgical intervention was $13.4 \pm 7.4$ days. The median follow-up period after the Fontan procedure was 16 months (range, 2-134 months).

\section{Spontaneously Closed Fenestrations}

There was spontaneous closure of the fenestration in $5(22 \%)$ patients (Table 1). One of these did not tolerate this closure and has had a transplantation. The other 4 patients are clinically stable. The size of the fenestrations varied from 2 punches of $2.5 \mathrm{~mm}(\mathrm{n}=2)$, a single $4-m m$ punch $(n=2)$, and a single $5-m m$ punch $(n=1)$. There was no correlation between the size of fenestration created and the likelihood of closure.

\section{Catheterization Laboratory Closure of Fenestrations}

Data on catheterization laboratory closure of fenestrations are shown in Table 1. Three patients were referred to the catheterization laboratory for device closure of the fenestration, of which 2 underwent device placement after favorable hemodynamics were demonstrated on test occlusion of the fenestration. The patients were referred for device closure because of desaturation in 2 patients and persistent headaches in the third. There were no infarcts seen on brain imaging in the patient with headaches, and the headaches have persisted after device closure.

\section{Patent Fenestrations}

There were 20 patients with complete data, of whom 14 had patent fenestrations. The cohort was divided into 3 groups on the basis of fenestration status on the most recent echocardiogram: group 1, 